\title{
The Relationship between Vascular Endothelial Growth Factor 1154G/A Polymorphism and Recurrent Implantation Failure
}

\author{
Laura D. Vagnini ${ }^{a}$ Adriana M. Nascimento ${ }^{a}$ Maria do Carmo T. Canas ${ }^{a}$ \\ Adriana Renzi $^{a}$ Gabriela R. Oliveira-Pelegrin ${ }^{a}$ Claudia G. Petersen ${ }^{a, b}$ \\ Ana L. Mauria, b João Batista A. Oliveira ${ }^{a, b}$ Ricardo L.R. Baruffia, b \\ Mario Cavagnab José G. Franco Jr. ${ }^{a}{ }^{b}$ \\ ${ }^{a}$ Paulista Center for Diagnosis Research and Training, and ${ }^{b}$ Center for Human Reproduction Prof. Franco Jr., \\ Ribeirão Preto, Brazil
}

\section{Key Words}

Implantation failure - Single-nucleotide polymorphisms . Genetic biomarker - VEGF-1154G/A - Infertility · Assisted reproduction

\begin{abstract}
Objective: The aim of this study was to investigate the relationship between herpesvirus-associated ubiquitin-specific protease (HAUSP A/G, rs1529916), tumor protein p53 (TP53 Arg/Pro, rs1042522), leukemia inhibitory factor (LIF G/T, rs929271), glycoprotein 130 (gp130 A/T, rs1900173) and vascular endothelial growth factor (VEGF G/A, rs1570360) polymorphisms and recurrent implantation failure (RIF) in Brazilian women. Subjects and Methods: A total of 120 women with RIF (i.e. those with $\geq 5$ cleaved embryos transferred and a minimum of 2 failed in vitro fertilization/intracytoplasmic sperm injection attempts) were included. The control group involved 89 women who had experienced at least 1 live birth (without any infertility treatment). DNA was extracted from the peripheral blood of all participants, and the abovementioned single-nucleotide polymorphisms (SNPs) were genotyped by real-time polymerase chain reaction. The data were evaluated using Fisher's test. Results: A significant difference between the RIF and control groups was found in the
\end{abstract}

VEGF gene where the GG genotype showed a 2.1 -fold increased chance of not being included in the RIF group, while the presence of an A allele increased this risk 1.6-fold. No significant differences were found for the other polymorphisms. Conclusion: This study showed an association between the VEGF-1154G/A polymorphism and RIF in Brazilian women.

(c) 2015 S. Karger AG, Basel

\section{Introduction}

Recurrent implantation failure (RIF) can be defined as a clinical phenomenon that refers to a situation when, after the transfer of embryos, the implantation has repeatedly failed to reach a stage recognizable by ultrasonographic evidence of an intrauterine gestational sac [1].

In 'in vitro fertilization' (IVF) protocols, the implantation rate is approximately $25-40 \%$ [1], with unsuccessful cases commonly being associated with RIF, an unaddressed major cause of infertility that remains poorly understood.

RIF etiology can be grouped into 3 main categories: decreased endometrial receptivity, embryonic defects and unsynchronized dialogue between maternal and em-

\begin{tabular}{ll}
\hline KARGER 125.3 & $\begin{array}{l}\text { (2) 2015 S. Karger AG, Basel } \\
1011-7571 / 15 / 0246-0533 \$ 39.50 / 0 \quad \text { Karger }\end{array}$ \\
$\begin{array}{l}\text { E-Mail karger@karger.com } \\
\text { www.karger.com/mpp }\end{array}$ & $\begin{array}{l}\text { This is an Open Access article licensed under the terms of the } \\
\text { Creative Commons Attribution-NonCommercial 3.0 Un- } \\
\text { ported license (CC BY-NC) (www.karger.com/OA-license), } \\
\text { applicable to the online version of the article only. Distribu- } \\
\text { tion permitted for non-commercial purposes only. }\end{array}$
\end{tabular}

José G. Franco Jr.

Center for Human Reproduction Prof. Franco Jr

Avenida Joao Fiusa 689

Ribeirão Preto, Sao Paulo, 14025310 (Brazil)

E-Mail franco@crh.com.br 
bryonic tissues [2]. Successful implantation of the embryo in decidualized endometrial stroma is crucial for early pregnancy, and endometrial receptivity plays a key role in this process [2-4]. The effort to maximize implantation rates involves the search for molecular markers of endometrial receptivity.

Genetic factors appear to be highly associated with these etiologies and RIF [5]. Overexpression or underexpression of genes that encodes the proteins necessary for successful implantation may be a reason for decreased endometrial receptivity [6]. Single-nucleotide polymorphisms (SNPs) in the p53 pathway have been linked to fertility in humans $[7,8]$. An important regulator of this pathway is herpesvirus-associated ubiquitin-specific protease (HAUSP), a specific deubiquitinase that stabilizes the $\mathrm{p} 53$ protein $[7,8]$. Protein $\mathrm{p} 53$-encoding by the $\mathrm{p} 53$ tumor suppressor gene (TP53), in turn, plays a critical role in regulating maternal reproduction and blastocyst implantation via the regulation of the expression of the leukemia inhibitory factor $(L I F)$ and vascular endothelial growth factor (VEGF) genes [8-10].

LIF is a pleiotropic cytokine of the interleukin 6 family, with a variety of effects on many different cell types $[11,12]$. In the reproductive system, LIF is produced and secreted by the endometrial glands of the uterus and plays an essential role in blastocyst implantation [1113]. It acts via binding to LIF receptor and recruitment of its coreceptor glycoprotein 130 (gp130), forming high-affinity signaling complexes $[4,12,13]$. LIF expression is higher during the onset of implantation than in other phases of a woman's cycle, preparing the uterus to be receptive to the blastocyst $[4,7,14]$. Following the invasion of the blastocyst into the endometrium, it must stimulate its own blood supply; this involves VEGF signaling to increase angiogenesis and vascularization [14, 15].

Given the importance of these genes in embryo implantation, a better understanding of the association between the polymorphisms in the genes mentioned above and RIF may improve the ability to diagnose and potentially treat, thereby increasing a couple's chances of conception [16].

The polymorphisms in genes that encode the important proteins that are functionally responsible for endometrial receptivity and their association with RIF have already been reported $[2,4,8]$. However, in women with RIF, the variable prevalence of such polymorphisms among ethnic groups, along with the high occurrence and the 'diagnostic gap' of this situation, highlights the needs for further investigation in different ethnic groups. There- fore, the aim of this study was to investigate the relationship between selected polymorphisms in the HAUSP, TP53, LIF, gp130 and VEGF genes in women from all over Brazil presenting with RIF after IVF/ICSI (intracytoplasmic sperm injection) treatment.

\section{Subjects and Methods}

\section{Study Participants}

Written informed consent was obtained from all the participating women and the Institutional Ethics Committees approved the study. The study patients were women presenting with RIF, and a total of 120 women subjected to IVF/ICSI protocols between 2011 and 2014 in the Center for Human Reproduction were included. All women enrolled in the study group met the following inclusion criteria: $\geq 5$ cleaved embryos (of good morphological quality) had been transferred and $\geq 2$ failed IVF/ICSI attempts (an RIF definition), a maternal age $\leq 39$ years (at the time of embryo transfer), a normal karyotype and negative for uterine defects, ultrasonographic evidence of hydrosalpinx, infections, endocrine problems, coagulation defects or thrombophilia and autoimmune defects (including antiphospholipid antibodies).

The control group consisted of 89 postmenopausal volunteers who had had at least 1 live birth (without infertility treatment) and with no history of recurrent miscarriage. This inclusion criterion was chosen based on the literature $[17,18]$, with the important bias of avoiding possible miscarriage after the women were recruited for the study.

\section{Genotyping}

A sample of peripheral venous blood from each woman was collected in an EDTA-containing tube. The DNA was extracted using QIAamp ${ }^{\circledR}$ DNA blood mini kit (Qiagen, Hilden, Germany) following the manufacturer's instructions. The chosen SNPs were: HAUSP A/G, rs1529916, C_9688119_1; TP53 72 (Arg/Pro, rs1042522, C_2403545_10); LIF G/T, rs929271, C_7545904_10; gp130 A/T, rs1900173, C_12014431_10; VEGF -1154G/A, rs1570360, C_1647379_10. The genotyping was performed by real-time polymerase chain reaction (PCR) amplification, using a TaqMan ${ }^{\circledR}$ SNP genotyping assay following the manufacturer's instructions with a $10-\mu \mathrm{l}$ composition consisting of $1 \mu \mathrm{l}$ genomic DNA (100 ng/ $\mu \mathrm{l}), 5 \mu \mathrm{l}$ UMM (TaqMan genotyping master mix), $0.5 \mu \mathrm{l}$ of each probe and $3.5 \mu \mathrm{LNase}$-free water. The amplification protocol was performed as following: denaturation at $95^{\circ} \mathrm{C}$ for 10 min, 40 cycles at $95^{\circ} \mathrm{C}$ for $15 \mathrm{~s}$ and at $60^{\circ} \mathrm{C}$ for $1 \mathrm{~min}$. The products were analyzed on the Applied Biosystems ${ }^{\circledR}$ TaqMan genotype software v1.3. Some samples were also sequenced to validate the genotyping results.

\section{Statistical Analysis}

Statistical analysis was performed using StatsDirect v2.7.9 software and the Hardy-Weinberg equilibrium was performed using an online calculator, available on http://ihg.gsf.de. The differences in the frequencies of SNP genotypes and/or alleles in the RIF and control groups were evaluated using Fisher's test. A p value $<0.05$ was considered statistically significant. The odds ratio (OR) was calculated for allele frequencies and grouped genotypes. 
Table 1. Characteristics of the women with RIF and the control group

\begin{tabular}{lcc}
\hline Variables & RIF & Controls \\
\hline Number of women & 120 & 89 \\
Age, years & $34.6 \pm 2.9$ & $51.4 \pm 11.9$ \\
Live births, n & - & $2.4 \pm 0.9$ \\
Previous implantation failures, $\mathrm{n}$ & $3.6 \pm 1.5$ & - \\
Previous embryos transferred, $\mathrm{n}$ & $8.9 \pm 4.6$ & - \\
Infertility diagnosis (etiology) & & - \\
$\quad$ Male & $40.8 \%(49 / 120)$ & - \\
$\quad$ Idiopathic & $20.0 \%(24 / 120)$ & - \\
$\quad$ Endometriosis & $15.0 \%(18 / 120)$ & - \\
$\quad$ Tuboperitoneal & $11.7 \%(14 / 120)$ & - \\
$\quad$ Male + endometriosis & $5.8 \%(7 / 120)$ & - \\
$\quad$ Tuboperitoneal + endometriosis & $3.3 \%(4 / 120)$ & - \\
$\quad$ Male + tuboperitoneal & $2.5 \%(3 / 120)$ & - \\
$\quad$ Male + tuboperitoenal + & & - \\
$\quad$ endometriosis & $0.8 \%(1 / 120)$ & - \\
\hline
\end{tabular}

\section{Results}

The characteristics of the women included in the RIF and control groups are given in table 1.

Although this was a small study, the genotype frequencies observed are in agreement with the Hardy-Weinberg equilibrium law.

The genotypic and allelic frequencies of HAUSP, TP53, $L I F, g p 130$ and VEGF among all women from the RIF and control groups are given in table 2 . The polymorphism studied in the HAUSP gene, a regulator of the p53 pathway, showed an apparent prevalence of GG homozygous genotype as well as $\mathrm{G}$ allele in both the RIF and control groups (OR 1.01, 95\% CI 0.65-1.59). For the TP53 gene, the investigation of polymorphism revealed $50.0 \%$ of a heterozygous genotype in the women presenting with RIF. In the control group, the Arg/Arg genotype was slightly more frequent (54.0\%) than in the RIF group (not statistically significant). However, in both groups, the Arg allele had a frequency of approximately 70\% (OR 1.11, 95\% CI 0.71-1.74). The analysis of LIF gene polymorphisms appeared to show a prevalence of heterozygous genotype in both groups $(58.3 \%$ in the RIF group and $52.8 \%$ in the control group) with a $\mathrm{T}$ allele frequency of $63.3 \%$ in the RIF group and $68.0 \%$ in the control group (OR $1.22,95 \%$ CI $0.79-1.89$ ). The gp130 polymorphism seemed to show a prevalence of the AA genotype in both groups, with the frequency of the A allele being $90.4 \%$ in the RIF group and $87.1 \%$ in the control group (OR 1.40, 95\% CI $0.72-2.71$ ). For the VEGF -1154G/A polymor-
Table 2. Genotypic and allelic frequencies of the HAUSP, TP53, LIF, gp130 and VEGF polymorphisms among women with RIF $(\mathrm{n}=120)$ and the control group $(\mathrm{n}=89)$

\begin{tabular}{|c|c|c|c|}
\hline & $\begin{array}{l}\text { RIF, } \\
\text { n (\%) }\end{array}$ & $\begin{array}{l}\text { Controls, } \\
\mathrm{n}(\%)\end{array}$ & $\mathrm{p}$ value \\
\hline \multicolumn{4}{|l|}{ HAUSP } \\
\hline \multicolumn{4}{|l|}{ Genotype } \\
\hline $\mathrm{G} / \mathrm{G}$ & $58(48.3)$ & $45(50.6)$ & \multirow{3}{*}{0.84} \\
\hline $\mathrm{A} / \mathrm{G}$ & $53(44.2)$ & $36(40.4)$ & \\
\hline $\mathrm{A} / \mathrm{A}$ & $9(7.5)$ & $8(9.0)$ & \\
\hline \multicolumn{4}{|l|}{ Allele } \\
\hline G & $169(70.4)$ & $126(70.8)$ & \multirow[b]{2}{*}{0.93} \\
\hline A & $71(29.6)$ & $52(29.2)$ & \\
\hline \multicolumn{4}{|l|}{ TP53 } \\
\hline \multicolumn{4}{|l|}{ Genotype } \\
\hline Arg/Arg & $53(44.2)$ & $48(54.0)$ & \multirow{3}{*}{0.06} \\
\hline Arg/Pro & $60(50.0)$ & $31(34.8)$ & \\
\hline Pro/Pro & $7(5.8)$ & $10(11.2)$ & \\
\hline \multicolumn{4}{|l|}{ Allele } \\
\hline Arg & $166(69.2)$ & $127(71.3)$ & \multirow{2}{*}{0.63} \\
\hline Pro & $74(30.8)$ & $51(28.7)$ & \\
\hline \multicolumn{4}{|l|}{$L I F$} \\
\hline \multicolumn{4}{|l|}{ Genotype } \\
\hline $\mathrm{T} / \mathrm{T}$ & $41(34.2)$ & 37 (41.6) & \multirow{3}{*}{0.52} \\
\hline $\mathrm{G} / \mathrm{T}$ & $70(58.3)$ & $47(52.8)$ & \\
\hline $\mathrm{G} / \mathrm{G}$ & $9(7.5)$ & $5(5.6)$ & \\
\hline \multicolumn{4}{|l|}{ Allele } \\
\hline $\mathrm{T}$ & $152(63.3)$ & $121(68.0)$ & \multirow{2}{*}{0.32} \\
\hline G & $88(36.7)$ & $57(32.0)$ & \\
\hline \multicolumn{4}{|l|}{$g p 130$} \\
\hline \multicolumn{4}{|l|}{ Genotype } \\
\hline $\mathrm{T} / \mathrm{T}$ & $0(0.0)$ & $2(2.2)$ & \multirow{3}{*}{0.23} \\
\hline $\mathrm{A} / \mathrm{T}$ & $23(19.2)$ & $19(21.4)$ & \\
\hline $\mathrm{A} / \mathrm{A}$ & $97(80.8)$ & $68(76.4)$ & \\
\hline \multicolumn{4}{|l|}{ Allele } \\
\hline $\mathrm{T}$ & $23(9.6)$ & $23(12.9)$ & \multirow{2}{*}{0.28} \\
\hline $\mathrm{A}$ & $217(90.4)$ & $155(87.1)$ & \\
\hline \multicolumn{4}{|l|}{ VEGF } \\
\hline \multicolumn{4}{|l|}{ Genotype } \\
\hline $\mathrm{G} / \mathrm{G}$ & 45 (37.8) & $49(56.3)$ & \multirow{3}{*}{0.03} \\
\hline $\mathrm{A} / \mathrm{G}$ & $62(52.1)$ & $30(34.5)$ & \\
\hline $\mathrm{A} / \mathrm{A}$ & $12(10.1)$ & $8(9.2)$ & \\
\hline \multicolumn{4}{|l|}{ Allele } \\
\hline G & $152(63.9)$ & $128(73.6)$ & \multirow{2}{*}{0.04} \\
\hline $\mathrm{A}$ & $86(36.1)$ & $46(26.4)$ & \\
\hline
\end{tabular}

phism, a prevalence of heterozygosis was found in the RIF group; in the control group, a GG homozygous genotype was significantly more frequent $(\mathrm{p}=0.03$; table 2$)$ than in the RIF group. In this SNP, the G allele frequency was high in both groups $(63.9 \%$ in the RIF group and $73.6 \%$ 
Table 3. Odds ratio analysis of grouped genotypes of the HAUSP, TP53, LIF, gp130 and VEGF polymorphisms among women RIF and the control groups

\begin{tabular}{|c|c|c|c|}
\hline & OR & $95 \% \mathrm{CI}$ & $\begin{array}{l}\mathrm{p} \text { value } \\
\text { (Fisher's test) }\end{array}$ \\
\hline \multicolumn{4}{|l|}{ HAUSP } \\
\hline \multicolumn{4}{|l|}{ Genotype } \\
\hline $\begin{array}{l}\mathrm{G} / \mathrm{G} \\
\mathrm{G} / \mathrm{A}+\mathrm{A} / \mathrm{A}\end{array}$ & 1.09 & $0.61-1.96$ & 0.78 \\
\hline \multicolumn{4}{|l|}{ TP53 } \\
\hline \multicolumn{4}{|l|}{ Genotype } \\
\hline $\begin{array}{l}\text { Arg/Arg } \\
\text { Arg/Pro + Pro/Pro }\end{array}$ & 1.48 & $0.82-2.66$ & 0.21 \\
\hline \multicolumn{4}{|l|}{$L I F$} \\
\hline \multicolumn{4}{|l|}{ Genotype } \\
\hline $\begin{array}{l}\mathrm{T} / \mathrm{T} \\
\mathrm{G} / \mathrm{T}+\mathrm{G} / \mathrm{G}\end{array}$ & 1.37 & $0.74-2.51$ & 0.31 \\
\hline \multicolumn{4}{|l|}{$g p 130$} \\
\hline \multicolumn{4}{|l|}{ Genotype } \\
\hline $\begin{array}{l}\mathrm{T} / \mathrm{T} \\
\mathrm{A} / \mathrm{T}+\mathrm{A} / \mathrm{A}\end{array}$ & infinity & 0.25 -infinity & 0.18 \\
\hline \multicolumn{4}{|l|}{$V E G F$} \\
\hline \multicolumn{4}{|l|}{ Genotype } \\
\hline $\begin{array}{l}\mathrm{G} / \mathrm{G} \\
\mathrm{A} / \mathrm{G}+\mathrm{A} / \mathrm{A}\end{array}$ & 2.12 & $1.16-3.87$ & 0.01 \\
\hline
\end{tabular}

in the control group), showing significant differences between them ( $\mathrm{p}=0.04$; table 2$)$. However, in the RIF group, the presence of the A allele was more frequent and demonstrated a 1.6-fold increased risk of implantation failure (OR 1.57, 95\% CI 1.01-2.48, $\mathrm{p}=0.04$ ).

The study of the effect of the allele presence in each $\mathrm{SNP}$, isolating 1 homozygous genotype and then comparing this with the rest, showed a significant difference for VEGF -1154G/A polymorphism (GG vs. AG + AA). The patients with the GG genotype had a 2.1-fold chance of not being included in the RIF group (table 3 ). These findings corroborate the results shown in table 2.

\section{Discussion}

In this study, there was a significant difference only in the polymorphism of the VEGF gene, suggesting that the presence of the A allele is associated with RIF. However, the prevalence of alleles and genotypes of the other polymorphisms were also noteworthy. All these genes have been shown to be involved to an appropriate extent of trophoblastic proliferation and enzyme digestion, leading to a blastocyst invasion into the endometrium and the stimulation of angiogenesis $[4,9,19]$. The analysis of the polymorphisms in some of the genes involved in the p53 pathway (i.e. HAUSP, TP53, LIF and gp130) did not reveal any significant difference between genotypes in the RIF and control groups. The A allele for the A/G polymorphism (rs1529916) in the HAUSP gene has been shown to be associated with infertility [8]; however, in our study, a prevalence of $G$ allele and GG genotype were observed in both the control and RIF groups, with no prevalence of A allele in either group. The analysis of the TP53 polymorphism showed a prevalence of the heterozygous genotype in the RIF group. It has been shown that the Pro72 codon is involved with higher levels of G1 cell cycle arrest than the Arg72 codon [20]; this leads to decreasing proliferation that can cause inadequate trophoblastic growth. Therefore, the presence of the Pro allele in the heterozygous patients of the RIF group could have been responsible for the implantation failure. Although there was similar distribution of the Arg allele in the control and RIF groups, a prevalence of the Arg/Arg genotype was observed in the control group, similar to in other studies that showed a relationship between the Arg allele and regulated cell proliferation $[8,21,22]$.

Regarding the $\mathrm{p} 53$ pathway, no significant difference for the LIF polymorphism was found, although we did observe a prevalence of the T allele in both groups. Additionally, in the RIF group, the TT genotype was slightly more frequent than in the control group, thereby confirming the results of a study that demonstrated an association of the $\mathrm{G}$ allele with infertility [8].

The genotyping of the gp130 polymorphism showed similar distribution of the AA genotype in both groups, without any significant difference between them. The presence of the T allele was very rare, and the TT genotype was only observed in the control group, representing $2.2 \%$ of this population. This observation confirmed the study of Malki [23] who found similar values in the study of this polymorphism in women presenting with infertility of an unexplained cause.

A significant difference was found only in the VEGF gene; the A allele was more frequent in the RIF than in the control group. Furthermore, when comparing the presence of the A allele (AG + AA grouped genotypes) with the homozygous GG genotype, a significant difference was also found, suggesting that the A allele could be involved in RIF. In fact, the homozygosity of the VEGF $-1154 \mathrm{AA}$ gene has been associated with RIF $[14,19,24]$. VEGF is the best-characterized regulator of angiogenesis, 
an essential process for successful embryo implantation, since inadequate angiogenesis is related to implantation failure [25]. Polymorphisms of the VEGF gene have been correlated with variations in VEGF protein production [26]. The VEGF -1154AA polymorphism characterized in the promoter region of the VEGF gene [26] is a 'low expression' genotype, expected to result in low expression of VEGF protein, which may decrease angiogenesis and blastocyst invasion, thereby leading to implantation failure $[14,19,24]$.

We therefore speculate that a single gene mutation is not the only cause of reduced endometrium receptivity, which can result in implantation failure, but rather that a combination of mutations in the different genes involved in the implantation process could increase the risk of RIF.

\section{Conclusion}

In this study, we found an association of the VEGF polymorphism and RIF in Brazilian women. We did not find any association between the other gene polymorphisms studied and RIF. Further studies could lead us to a set of genetic biomarkers to define endometrial receptivity, which, in association with other clinical parameters, could contribute to diagnosis and treatment to reduce rates of RIF.

\section{Acknowledgement}

The authors wish to thank the nursing staff and laboratory technicians for their kind assistance during the study period.

\section{References}

1 Coughlan C, Ledger W, Wang Q, et al: Recurrent implantation failure: definition and management. Reprod Biomed Online 2014; 28:14-38.

2 Fatemi HM, Popovic-Todorovic B: Implantation in assisted reproduction: a look at endometrial receptivity. Reprod Biomed Online 2013;27:530-538.

3 Sharkey AM, Macklon NS: The science of implantation emerges blinking into the light. Reprod Biomed Online 2013;27:453-460.

-4 Fritz R, Jain C, Armant DR: Cell signaling in trophoblast-uterine communication. Int J Dev Biol 2014;58:261-271.

5 Christiansen OB, Nielsen HS, Kolte AM: Future directions of failed implantation and recurrent miscarriage research. Reprod Biomed Online 2006;13:71-83.

6 Madon PF, Athalye AS, Parikh FR: Polymorphic variants on chromosomes probably play a significant role in infertility. Reprod Biomed Online 2005;11:726-732.

7 Hu W, Zheng T, Wang J: Regulation of fertility by the 53 family members. Genes Cancer 2011;2:420-430.

-8 Kang HJ, Feng Z, Sun Y, et al: Single-nucleotide polymorphisms in the $\mathrm{p} 53$ pathway regulate fertility in humans. Proc Natl Acad Sci USA 2009; 106:9761-9766.

$9 \mathrm{Hu}$ W, Feng Z, Levine AJ: The regulation of human reproduction by $\mathrm{p} 53$ and its pathway. Cell Cycle 2009;8:3621-3622.
10 Farhang Ghahremani M, Goossens S, Haigh JJ: The p53 family and VEGF regulation: 'it's complicated'. Cell Cycle 2013;12:1331-1332.

-11 Giess R, Tanasescu I, Steck T, et al: Leukaemia inhibitory factor gene mutations in infertile women. Mol Hum Reprod 1999;5:581-586.

12 Lass A, Weiser W, Munafo A, et al: Leukemia inhibitory factor in human reproduction. Fertil Steril 2001;76:1091-1096.

13 Kimber SJ: Leukaemia inhibitory factor in implantation and uterine biology. Reproduction 2005;130:131-145.

14 Coulam CB, Jeyendran RS: Vascular endothelial growth factor gene polymorphisms and recurrent pregnancy loss. Am J Reprod Immunol 2008;59:301-305.

15 Torry DS, Leavenworth J, Chang M, et al: Angiogenesis in implantation. J Assist Reprod Genet 2007;24:303-315.

16 Laufer N, Simon A: Recurrent implantation failure: current update and clinical approach to an ongoing challenge. Fertil Steril 2012;97: 1019-1020.

17 Al Sallout RJ, Sharif FA: Polymorphisms in NOS3, ACE and PAI-1 genes and risk of spontaneous recurrent miscarriage in the Gaza Strip. Med Princ Pract 2010;19:99-104.

18 Pietrowski D, Bettendorf H, Riener EK, et al: Recurrent pregnancy failure is associated with a polymorphism in the p53 tumour suppressor gene. Hum Reprod 2005;20:848-851.

19 Goodman C, Jeyendran RS, Coulam CB: Vascular endothelial growth factor gene polymorphism and implantation failure. Reprod Biomed Online 2008;16:720-723.
20 Pim D, Banks L: P53 polymorphic variants at codon 72 exert different effects on cell cycle progression. Int J Cancer 2004;108:196-199.

21 Corbo RM, Gambina G, Scacchi R: How contemporary human reproductive behaviors influence the role of fertility-related genes: the example of the p53 gene. PLoS One 2012; 7:e35431.

22 Kay C, Jeyendran RS, Coulam CB: P53 tumour suppressor gene polymorphism is associated with recurrent implantation failure. Reprod Biomed Online 2006;13:492-496.

23 Malki M: Correlations between unexplained infertility and single nucleotide polymorphism in the genes of leukemia inhibitory factor receptor and gp130. Department of Medical Biochemistry and Microbiology. Uppsala, Uppsala University Publications, 2010.

24 Goodman C, Jeyendran RS, Coulam CB: P53 tumor suppressor factor, plasminogen activator inhibitor, and vascular endothelial growth factor gene polymorphisms and recurrent implantation failure. Fertil Steril 2009;92:494498.

25 Kapiteijn K, Koolwijk P, van der Weiden RM, et al: Human embryo-conditioned medium stimulates in vitro endometrial angiogenesis. Fertil Steril 2006;85(suppl 1):1232-1239.

26 Brogan IJ, Khan N, Isaac K, et al: Novel polymorphisms in the promoter and $5^{\prime}$ UTR regions of the human vascular endothelial growth factor gene. Hum Immunol 1999;60: 1245-1249. 